\title{
Stability of the trastuzumab biosimilar ABP 980 compared to reference product after intravenous bag preparation, transport and storage at various temperatures, concentrations and stress conditions
}

\author{
Shon Crampton', BA; Alla Polozova', PhD; Darin Asbury², BS; Alexis Lueras², BS; Paul Breslin', BS; \\ Jane Hippenmeyer ${ }^{3}$, PharmD; Jennifer Litowski', PhD; Monica Goss' ${ }^{2}$, PhD
}

\begin{abstract}
Study objectives: To investigate the quality and in-use stability of diluted ABP 980 (a trastuzumab biosimilar) versus reference trastuzumab to mimic dosing in intravenous (IV) bags, transportation and extended storage prior to infusion.

Methods: Low dose (70 mg; $0.3 \mathrm{mg} / \mathrm{mL})$ and high dose $(1,200 \mathrm{mg} ; 3.8 \mathrm{mg} / \mathrm{mL})$ ABP 980 and reference trastuzumab solutions were prepared, light-protected and subjected to transportation simulation and storage $\left(2^{\circ} \mathrm{C}-8^{\circ} \mathrm{C}\right.$ or $30^{\circ} \mathrm{C}$ for 5 weeks, followed by 48 hours at $30^{\circ} \mathrm{C}$ ). Stability was assessed pre- and post-transport; at Weeks 1, 2, 4, and 5; at Week 5 after 48 hours at $30^{\circ} \mathrm{C}$; and pre- and postinfusion using an infusion pump.

Results: Across doses and temperatures, there was little change in high molecular weight species and no detectable loss in purity. Following storage, visible particles $(>125 \mu \mathrm{m})$ were intermittently observed for both products, with increased subvisible particles detected with low doses. Extended storage at $2^{\circ} \mathrm{C}-8^{\circ} \mathrm{C}$ did not lead to any significant loss in the active molecule, with consistent biological potency across doses and temperatures for both products. Higher-dose dilutions maintained pH closer to the initial formulation specifications.

Discussion: This study examined the impact of dilution, transport and extended storage at different temperatures on the stability of ABP 980 and reference trastuzumab. No major differences between the two products were observed.

Conclusion: Across storage temperatures, multiple stability-indicating assays demonstrated no clinically meaningful impact to product quality and stability for both ABP 980 and reference trastuzumab, which provides assurance that ABP 980 retains stability and activity over extended storage periods.
\end{abstract}

Keywords: ABP 980, biosimilar, stability, trastuzumab

Introduction/Study Objectives

In September 1998, trastuzumab (Herceptin ${ }^{\circledR}$ ) received US Food and Drug Administration (FDA) approval for the treatment of human epidermal growth factor receptor 2 (HER2)-positive metastatic breast cancer (BC), making it one of the first available targeted biological therapies [1]. This was followed by approval of trastuzumab by the European Medicines Agency (EMA) in August 2000 [2]. Trastuzumab, a recombinant humanized immunoglobulin G1 (IgG1) monoclonal antibody, targets the HER2 extracellular juxtamembrane domain, inhibiting HER2-dependent tumour proliferation and survival [3]. Since its original approval in 1998, the licensed indication of trastuzumab has expanded and now also includes HER2-positive early BC (eBC) and HER2-positive metastatic gastric or gastroesophageal junction adenocarcinoma (mGC). The impact of trastuzumab upon patients' lives has been profound, and in addition, its development has highlighted the importance of categorizing cancer according to its biological subtype. Unsurprisingly, with the patent expiry of trastuzumab, several trastuzumab biosimilars have been developed and approved, based upon the totality of evidence required to demonstrate biosimilarity [4]. As part of this evidence, a comparative clinical study is needed to confirm biosimilarity in a setting which is clinically relevant, has measurable endpoints, and can detect differences between treatments, if any exist [5].

ABP 980 (KANJINTI $^{\mathrm{TM}}$, Amgen Inc) is a trastuzumab biosimilar, which was approved for the treatment of HER2-positive early (neoadjuvant and adjuvant) and metastatic BC, and HER2 positive mGC by the EMA in March 2018 and by the FDA in June 2019 [6, 7]. Comprehensive physicochemical and functional characterization of ABP 980 was performed through a range of complementary analytical techniques [8]. Physicochemical comparisons included an assessment of structural features relating to its primary and higher-order structure, which showed that ABP 980 has the same amino acid sequence and similar post-translational modifications, product-related variants, and protein content as reference trastuzumab. The functional similarity of ABP 980 to reference trastuzumab was demonstrated using several in vitro binding and cell-based functional assays. These data showed that ABP 980 has similar HER2 kinetic binding properties and biological potency to reference trastuzumab [8]. In addition, ABP 980 has been found to have equivalent pharmacokinetics, safety and tolerability in healthy males [9]. Both trastuzumab and ABP 980 are produced using recombinant DNA technology in Chinese hamster ovary (CHO) cells $[10,11]$.

Neoadjuvant $\mathrm{BC}$ represents a sensitive setting for establishing

Author for correspondence: Shon Crampton, BA, Scientist, Amgen Inc, 360 Binney Street, Cambridge, MA 02142, USA

Submitted: 1 October 2019; Revised: 23 January 2020; Accepted: 6 February 2020; Published online first: 19 February 2020 
biosimilarity, with the possibility to assess pathologic complete response rates. The opportunity to continue with long-term monotherapy in the adjuvant setting is also well suited for assessing biosimilarity. This setting was chosen for the phase III LILAC trial, which evaluated the clinical safety and efficacy of ABP 980 versus reference trastuzumab in women with HER2-positive eBC [12]. Efficacy was found to be similar for the two agents in terms of pathological complete response rates; there were also comparable rates of grade $\geq 3$ adverse events in these treatment groups during the neoadjuvant and adjuvant phases of the study [12]. These LILAC study data were used to extrapolate the efficacy of ABP 980 across all reference trastuzumab indications [7].

In many countries, centralized pharmacies often prepare anticancer drug solutions, which are then transported to clinical sites for administration to patients. The logistics of centralized pharmacy requires holding the prepared solutions for longer durations than those currently recommended in product labels, as well as potentially requiring transportation to remote sites [13]. In order to ensure that they retain their 'physical, chemical, microbiological and biological properties within specified limits' [13], the 'in-use' stability assessment of anticancer drugs during their preparation, storage, transportation and administration is important. Stability studies carried out during drug development are designed to fulfil licensing label requirements and are often limited to 24 hours, even though chemical stability could be longer [13].

To assist centralized pharmacy requirements, we have conducted a comprehensive in-house study using a robust array of assays to investigate the quality and in-use stability of diluted IV formulations of ABP 980 in direct comparison with the reference trastuzumab under identical conditions to mimic dosing in IV bags, transportation and extended storage prior to infusion.

\section{Methods}

\section{Infusion bag preparation}

In total, eight IV bags (flexible polyolefin, $250 \mathrm{~mL}$ ) were prepared for testing, see Figure 1, comprising two low-dose (70 mg; $0.3 \mathrm{mg} / \mathrm{mL}$; selected as a worst-case low dose) and two highdose bags (1,200 mg; $3.8 \mathrm{mg} / \mathrm{mL}$ ) for ABP 980 and reference trastuzumab. Dosed IV bags were placed in boxes, protected from light and subjected to mechanical stress (transportation simulation), which involved two drops from a height of $\sim 46 \mathrm{~cm}$ (18 inches), and subsequent transportation steel spring truck vibration simulation for two hours followed by a further two drops.
The dosed IV bags were then placed at either $2^{\circ} \mathrm{C}-8^{\circ} \mathrm{C}$ or $30^{\circ} \mathrm{C}$ for 5 weeks, followed by 48 hours at $30^{\circ} \mathrm{C}$ in order to simulate worst-case storage conditions at the patient administration site. At each timepoint (see below), $30 \mathrm{~mL}$ aliquots were taken from the IV bags using an un-siliconized syringe and needle, and the post-infusion sample was the remainder of the IV bag volume at the end of the study. All samples that were diluted in $0.9 \%$ saline required concentration from $0.3 \mathrm{mg} / \mathrm{mL}$ and $3.8 \mathrm{mg} / \mathrm{mL}$ to $>5 \mathrm{mg} / \mathrm{mL}$, and buffer exchange into formulation buffer prior to size-exclusion ultra-high-performance liquid chromatography (SE-UHPLC), cation-exchange high-performance liquid chromatography (CEX-HPLC) and reduced capillary electrophoresis (rCE) sodium dodecyl sulphate (SDS) analysis.

\section{Assessment of drug product quality and stability}

Assessments were made at the following timepoints: pre- and post-transportation simulation (Weeks -1 and 0 , respectively), at Weeks 1, 2, 4, and 5; and at Week 5+ following 48 hours at $30^{\circ} \mathrm{C}$ pre-infusion, and also post-infusion, see Figure 1.

Visual inspection, and protein concentration and recovery Visual observation was used to assess aggregation and particle formation; particles sized $>125 \mu \mathrm{m}$ were monitored and were deemed likely proteinaceous. Samples were collected in $30 \mathrm{~mL}$ polyethylene terephthalate glycol (PETG) containers and inspected by a trained visual inspector in a visual inspection booth with non-reflecting black and white background under fluorescent lighting conditions; the acceptable light intensity value for detection was $>2,000$ lux. Ultraviolet-visible (UV-Vis) spectroscopy was used to evaluate protein concentration and percentage recovery. Concentration determinations were performed using SoloVPE UV-Vis spectroscopy using the extinction coefficient of 1.5 for a $1 \mathrm{mg} / \mathrm{mL}$ solution at $280 \mathrm{~nm}$. Percent recovery was calculated by:

$\%$ Recovery $=\frac{\text { Measured concentration post-infusion }}{\text { Measured concentration pre-transportation simulation }} \times 100$

$p H$

$\mathrm{pH}$ tests were carried out on post-transportation samples at Week 0. A Mettler Toledo SevenMulti $\mathrm{pH}$ meter was calibrated using $\mathrm{pH}$ 4, 7 and 10 standards. The probe used was a Mettler Toledo InLab Micro. pH readings were taken on samples after they had equilibrated to room temperature.

Figure 1: Study design

Sample collection/analysis timepoints:
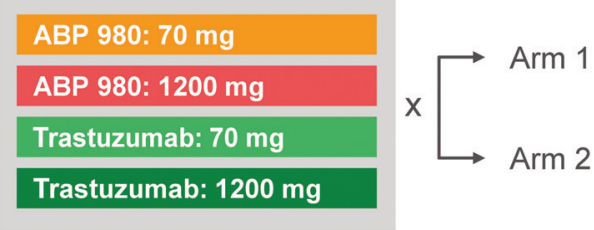

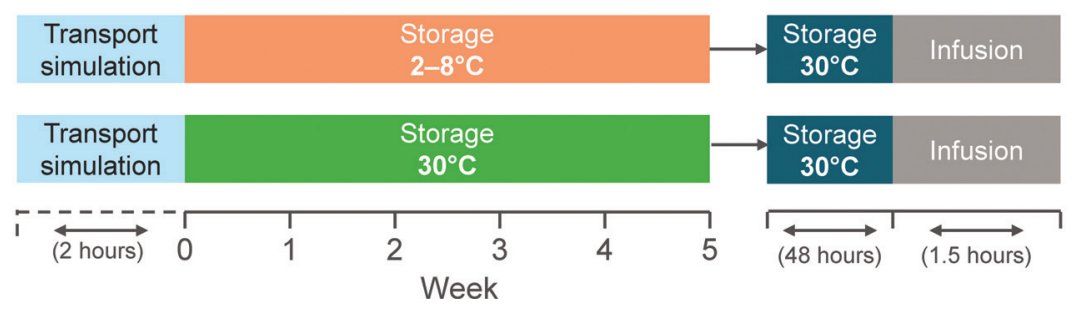




\section{Aggregation}

Aggregation was assessed through quantification of high molecular weight (HMW) species using SE-UHPLC. Briefly, $60 \mu \mathrm{g}$ of each sample was injected onto a Waters BEH200, $1.7 \mu \mathrm{m}$ particle size, $4.6 \times 150 \mathrm{~mm}$ column and eluted isocratically over 6 minutes with $100 \mathrm{mM}$ sodium phosphate, $250 \mathrm{mM}$ sodium chloride, $\mathrm{pH} 6.8$, with a flow rate of $0.4 \mathrm{~mL} / \mathrm{min}$ using a Waters Acquity system running Empower software. Absorbance was measured at $280 \mathrm{~nm}$ over 6 minutes. Peak areas in the chromatogram were used to quantify the amounts of HMW species.

\section{Purity}

Purity was examined using CEX-HPLC and rCE-SDS assays.

For CEX-HPLC, $170 \mu \mathrm{g}$ of each sample was injected on an Agilent BioMab, NP5, $4.6 \times 250 \mathrm{~mm}$ column and eluted with a gradient from $20 \mathrm{mM}$ sodium phosphate, $\mathrm{pH}$ 6.9-20 mM sodium phosphate, $500 \mathrm{mM}$ sodium chloride, $\mathrm{pH} 6.9$ using an Agilent 1200 HPLC running Chromeleon software. Absorbance was measured at $280 \mathrm{~nm}$ over 60 minutes. All samples that were diluted into $0.9 \%$ saline required concentration from $0.3 \mathrm{mg} / \mathrm{mL}$ and $3.8 \mathrm{mg} /$ $\mathrm{mL}$ to $>5 \mathrm{mg} / \mathrm{mL}$, and buffer exchange into formulation buffer. Prior to injection and CEX-HPLC analysis, samples were diluted to $2 \mathrm{mg} / \mathrm{mL}$ using $20 \mathrm{mM}$ sodium phosphate, $\mathrm{pH} 6.9$ [mobile phase A] and CEX-HPLC analysis.

For the rCE-SDS assays, samples were reduced and denatured using $\beta$-mercaptoethanol and SDS; and injected on $50 \mu \mathrm{m}$ internal diameter bare fused silica capillary. Protein peaks were detected by a photodiode array detector as they passed through at $220 \mathrm{~nm}$.

\section{Potency by proliferation inhibition bioassay}

A cell-based proliferation inhibition assay used human breast tumour cells (BT-474) expressing HER2 receptors to evaluate potency [8]. BT-474 cells were incubated with varying concentrations of ABP 980 reference standard, control and test samples. The biological activity of the test sample was determined by comparing the ABP 980 test sample or the trastuzumab test sample response to that of reference trastuzumab standard response (relative potency).

\section{Subvisible particle counting}

Subvisible particles were counted by high accuracy (HIAC) light obscuration and analysed using a HIAC/Royco liquid-borne particle counter system with a high-rate linear detector (HRLD)150 laser using Pharm Spec software. Samples were degassed at 75 Torr for 1 hour prior to analysis. Four samples of $1 \mathrm{~mL}$ were taken, with the first sample being discarded and the last three averaged to report the data as mean \pm standard deviation (SD).

\section{Results}

Visual inspection, and protein concentration and recovery

Particles of size $>125 \mu \mathrm{m}$ were intermittently observed for both $\mathrm{ABP} 980$ and reference trastuzumab, whether stored at $2^{\circ} \mathrm{C}-8^{\circ} \mathrm{C}$ for 5 weeks and then $30^{\circ} \mathrm{C}$ for 48 hours, or at $30^{\circ} \mathrm{C}$ for 5 weeks and then for a further 48 hours at $30^{\circ} \mathrm{C}$, see Figure 2. The percentage protein recovery, calculated from UV-Vis protein concentration measurements was $98 \%-100 \%$ for all samples tested, indicating no significant loss of protein due to adsorption to the intravenous (IV) bag and infusion line.

\section{pH}

The higher-dose dilutions maintained the $\mathrm{pH}$ closer to the initial formulation specifications as compared to the lower doses for

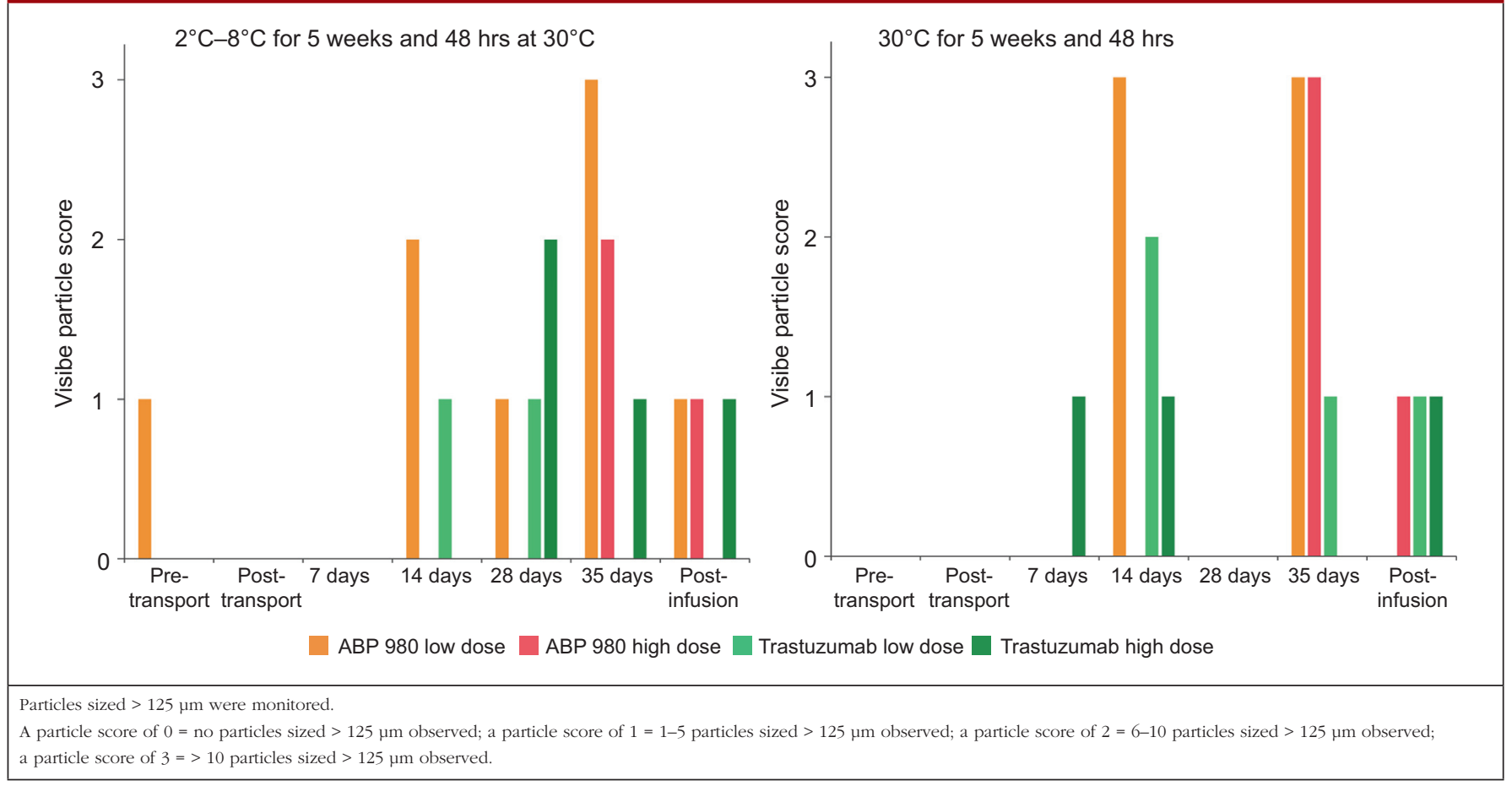




\section{Figure 3: pH measurements at different temperatures and dilutions}

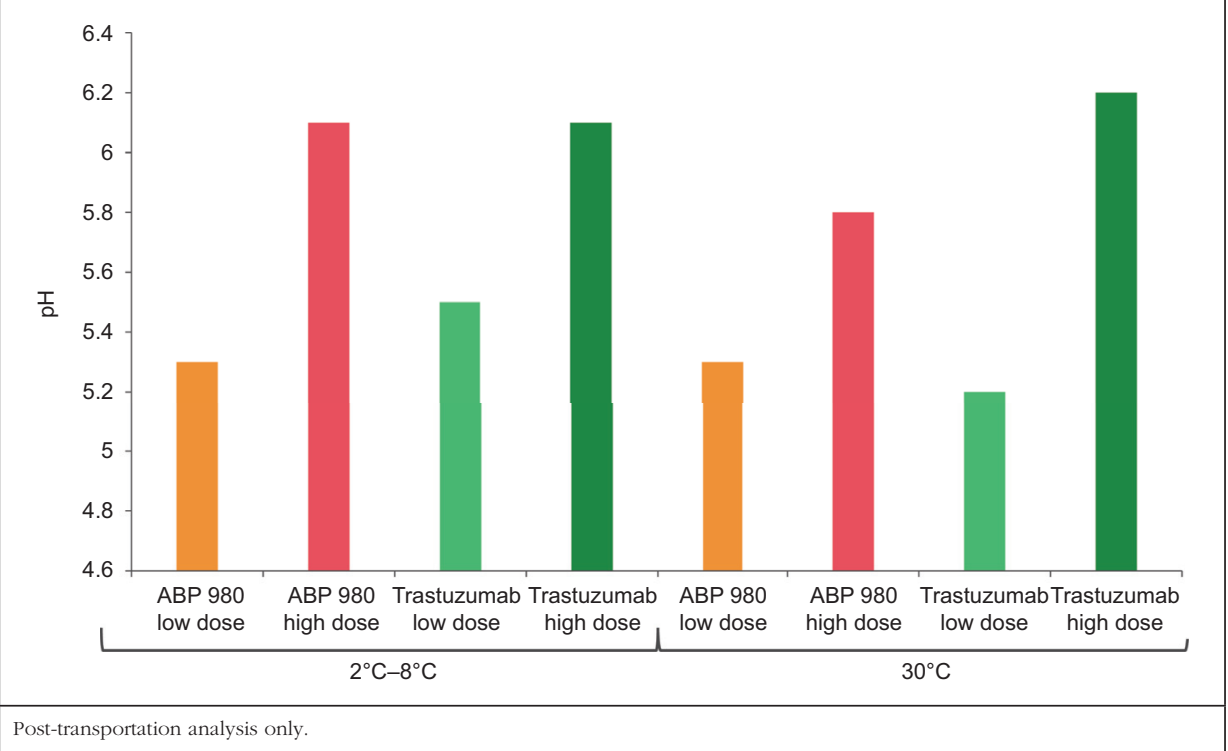

zumab with respect to aggregation rates, when subjected to mechanical stress to simulate transportation and then stored at either $2^{\circ} \mathrm{C}-8^{\circ} \mathrm{C}$ or $30^{\circ} \mathrm{C}$ for 5 weeks, and then at $30^{\circ} \mathrm{C}$ for 48 hours.

\section{Purity by CEX-HPLC}

Trastuzumab is sensitive to deamidation and isoaspartate formation at certain Asn/ Asp residues, which lead to a reduction of biological activity [14]. Deamidation at Asn30 causes a 30\% drop in potency, compared with the main species, and isomerization at Asp102 results in only $9 \%$ to $21 \%$ of the potency of the main species [14]. To monitor deamidation and isoaspartate formation, a CEX-HPLC method was developed that resolves these species chromatographically.

Upon storage at $2^{\circ} \mathrm{C}-8^{\circ} \mathrm{C}$ for 5 weeks followed by exposure to $30^{\circ} \mathrm{C}$ for 48 hours, CEX-HPLC analysis of reconstituted trastuzumab (either ABP 980 or both ABP 980 and the reference trastuzumab, see Figure 3. For the low-dose $(0.3 \mathrm{mg} / \mathrm{mL})$ dilutions, the small volume of drug product used $(3.3 \mathrm{~mL}$ in a $250 \mathrm{~mL}$ IV bag) led to dilution of the L-histidine buffer and a drop in $\mathrm{pH}$ to as low as $\mathrm{pH}$ 5.2.

\section{Aggregation}

There was little change in the percentage of high molecular weight (HMW) species across doses and temperatures on SE-UHPLC for either ABP 980 or the reference trastuzumab, see Figure 4. These data indicate the in-use stability of ABP 980 and reference trastu- reference product) demonstrated no significant loss in main peak (intact molecule). Upon exposure to $30^{\circ} \mathrm{C}$ over 5 weeks and 48 hours, reconstituted ABP 980 as well as reference trastuzumab were both sensitive to chemical degradation over time at $30^{\circ} \mathrm{C}$, see Figure 5, as expected during storage at room temperature [15].

\section{Purity by rCE-SDS}

There was no detectable loss in purity across doses and temperatures for either ABP 980 or reference trastuzumab, indicating stability with respect to fragmentation, see Figure 6.

\section{Figure 4: Aggregation analysis by SE-UHPLC upon exposure to $30^{\circ} \mathrm{C}$}

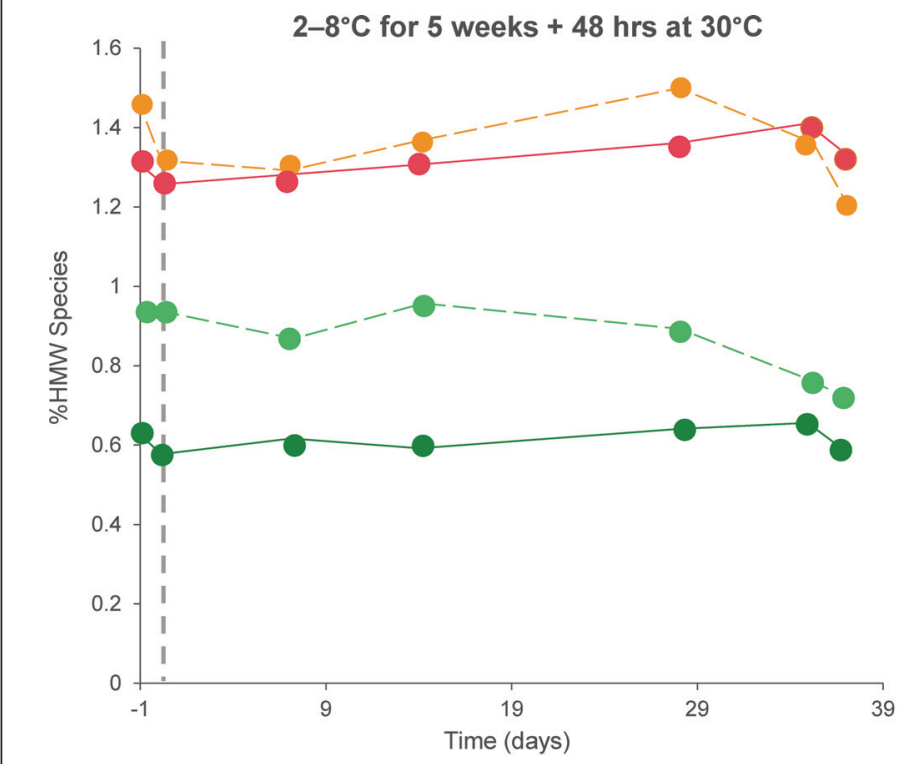

- $-\mathrm{ABP} 980$ low dose _ ABP 980 high dose

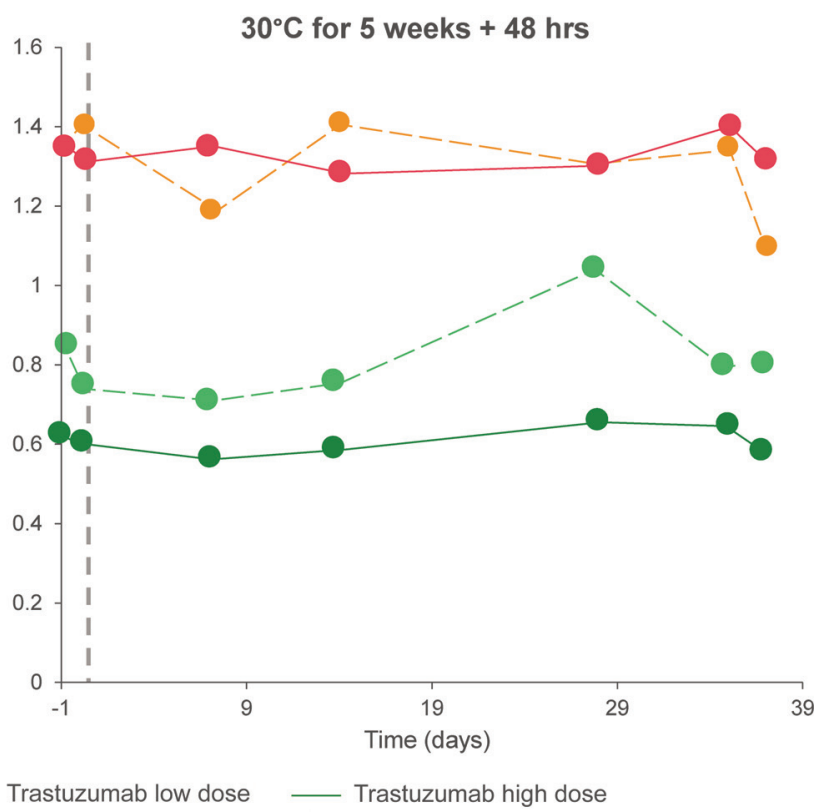

\%HMW: percentage of high molecular weight species; SE-UHLPC: size-exclusion ultra-high-performance liquid chromatography. 


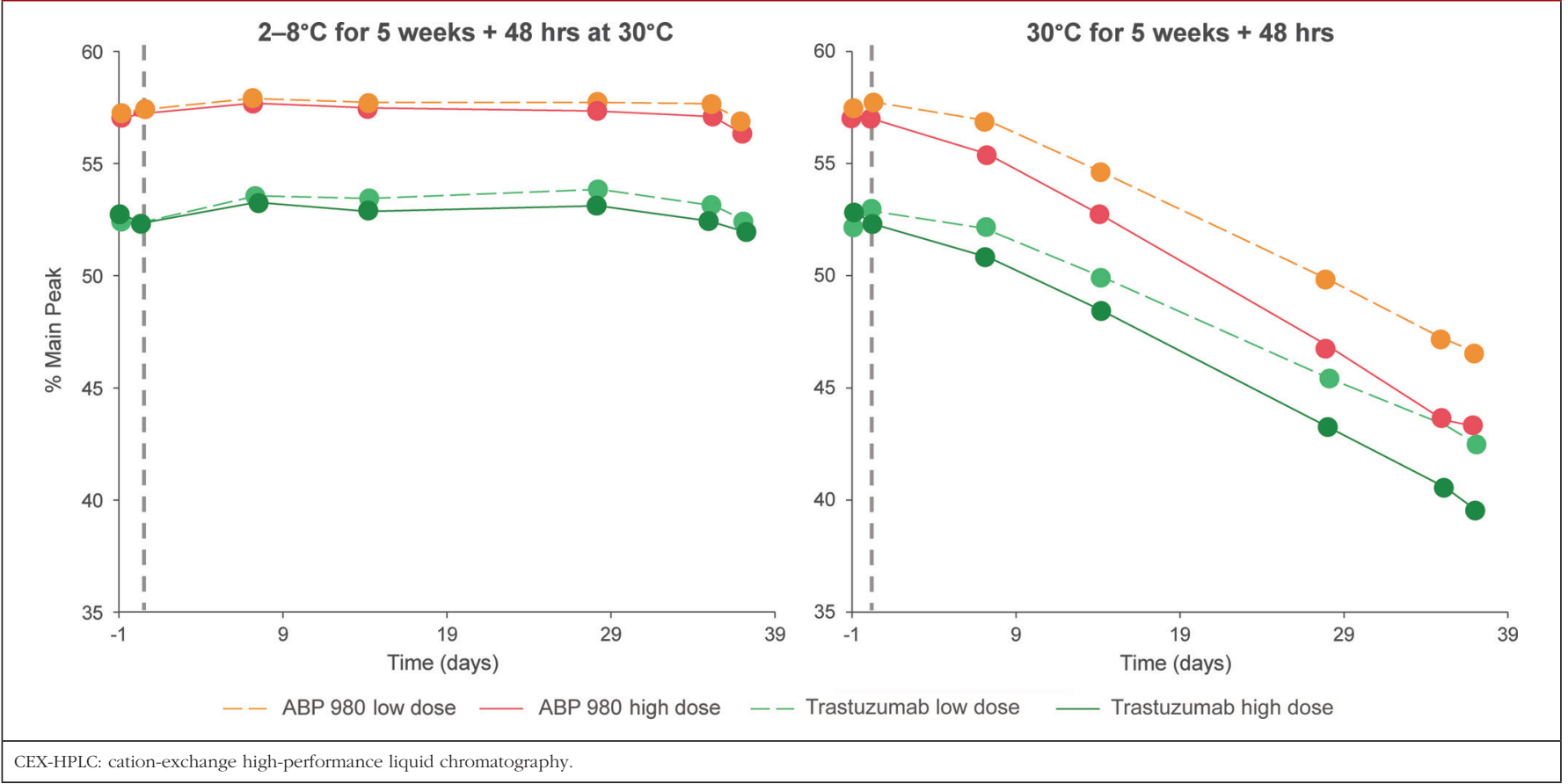

Figure 6: Purity* by rCE-SDS assay upon exposure to $30^{\circ} \mathrm{C}$
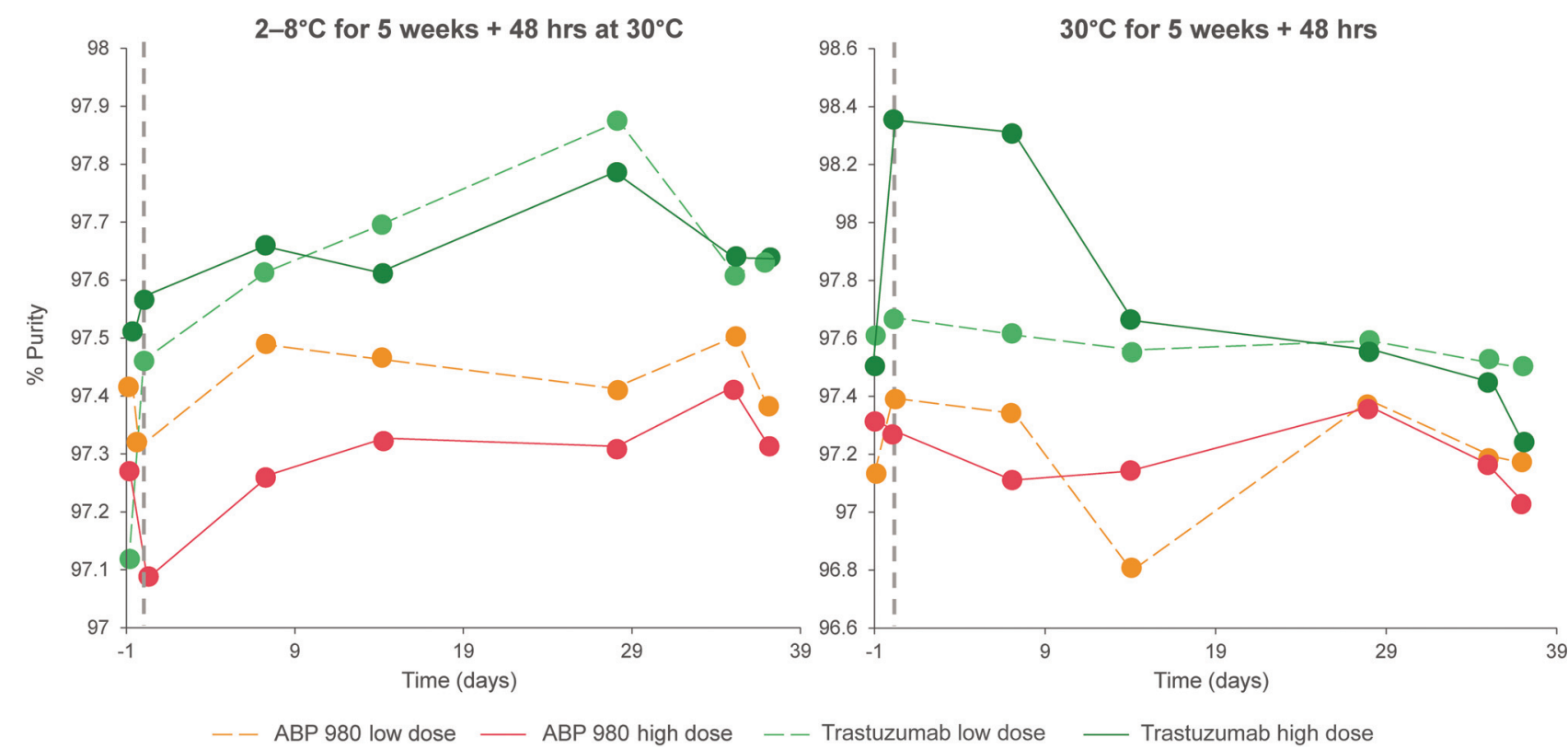

$* \%$ heavy chain $+\%$ light chain

rCE-SDS: reduced capillary electrophoresis sodium dodecyl sulphate.

\section{Potency by inhibition of cell proliferation bioassay}

There was consistent biological potency of between 97\%-114\% across doses (97\%-104\% for low dose, and 102\%-114\% for high dose) and temperatures $\left(98 \%-114 \%\right.$ at $2^{\circ} \mathrm{C}-8^{\circ} \mathrm{C}$, and $97 \%-113 \%$ at $30^{\circ} \mathrm{C}$ ) for both ABP 980 and reference trastuzumab, see Table 1.

\section{Subvisible particle counting by HIAC}

Analysis of subvisible particle levels by HIAC showed that these were generally consistent between ABP 980 and reference trastuzumab at both low and high dose concentrations. Increased particle counts $\geq 10 \mu \mathrm{m}$ were observed with the low 
Table 1: Cell proliferation inhibition bioassay in a human breast tumour cell line (BT-474)

\begin{tabular}{|l|l|}
\hline Sample (post-infusion) & \% relative potency \\
\hline ABP 980, low dose, $2^{\circ} \mathrm{C}-8^{\circ} \mathrm{C}$ & 98 \\
\hline ABP 980, high dose, $2^{\circ} \mathrm{C}-8^{\circ} \mathrm{C}$ & 102 \\
\hline Trastuzumab, low dose, $2^{\circ} \mathrm{C}-8^{\circ} \mathrm{C}$ & 101 \\
\hline Trastuzumab, high dose, $2^{\circ} \mathrm{C}-8^{\circ} \mathrm{C}$ & 114 \\
\hline ABP 980, low dose, $30^{\circ} \mathrm{C}$ & 97 \\
\hline ABP 980, high dose, $30^{\circ} \mathrm{C}$ & 106 \\
\hline Trastuzumab, low dose, $30^{\circ} \mathrm{C}$ & 104 \\
\hline Trastuzumab, high dose, $30^{\circ} \mathrm{C}$ & 113 \\
\hline
\end{tabular}

doses of both ABP 980 and reference trastuzumab, see Figure 7. Overall, the $\geq 2 \mu \mathrm{m}$ particle data were comparable for ABP 980 and reference trastuzumab and indicate that there are no increases in subvisible particle levels over time, see Figure 8.

\section{Discussion}

In-use drug stability studies, i.e. those that are not designed to fulfil label licensing requirements, are relevant in 'real-world' hospital pharmacy settings, as they provide insight into the impact that reconstitution and dilution, transportation, and storage conditions prior to infusion, have upon a drug. Our study utilized a robust range of stability-indicating assays to consider the impact of potential real-life conditions on the quality and stability of high and low dose ABP 980, compared with reference trastuzumab. The impact of mechanical stress, e.g. simulated transportation by a steel spring truck, and extended storage $\left(35\right.$ days at $2^{\circ} \mathrm{C}-8^{\circ} \mathrm{C}$ or $30^{\circ} \mathrm{C}$, followed by $30^{\circ} \mathrm{C}$ for 48 hours), were evaluated in terms of product quality, purity and activity. In addition, both products were tested for product quality before and after administration using an infusion pump.

Our findings show consistently similar product quality between ABP 980 and reference trastuzumab. Although ABP 980 had a higher initial level of HMW species than reference trastuzumab, rates of aggregation were similar for both products. The initial difference, which could be due to factors including age of the starting material or lot-to-lot variability, did not impact the inuse stability. With regard to the increased particle counts with the low doses of both ABP 980 and reference trastuzumab, we can hypothesize that this might be due to dilution of the surfactant (polysorbate 20) below its effective concentration, as well as the agitation induced by transportation simulation. For the lowest-dose dilutions (which are rarely used clinically), the final theoretical concentration of polysorbate 20 in the IV bag is $0.0001 \%$, whereas for higher-dose dilutions it is $0.0014 \%$. Furthermore, subvisible particle data met standard criteria according to US Pharmacopeia particle determination: guidance for parenteral products (USP <787>) and European Pharmacopoeia 9.0 (Ph.Eur. 2.9.19) specifications for extended storage at $2^{\circ} \mathrm{C}-8^{\circ} \mathrm{C}$.

CEX-HPLC indicated that storage at $30^{\circ} \mathrm{C}$ led to changes in ABP 980 and reference trastuzumab over time, changes that were not seen when stored at $2^{\circ} \mathrm{C}-8^{\circ} \mathrm{C}$ over the period of time tested. Despite the changes in $\mathrm{ABP} 980$ and reference trastuzumab when stored at $30^{\circ} \mathrm{C}$, these did not appear to affect the outcomes of other tests (including biological activity). In fact, an NHS Foundation Trust in England has reviewed the information derived from this study and has issued an interpretation of the data and a recommendation for extended storage of 28 days in a refrigerator for dilutions of $0.3 \mathrm{mg} / \mathrm{mL}-3.8 \mathrm{mg} / \mathrm{mL}$ in saline solution [16]. They considered that room temperature data (at $30^{\circ} \mathrm{C}$ ) indicated a robust margin of safety for the shelf-life of $\mathrm{ABP}$

\section{Figure 7: Subvisible particle counts $(\geq 10 \mu \mathrm{m}) *$ upon exposure to $30^{\circ} \mathrm{C}$}

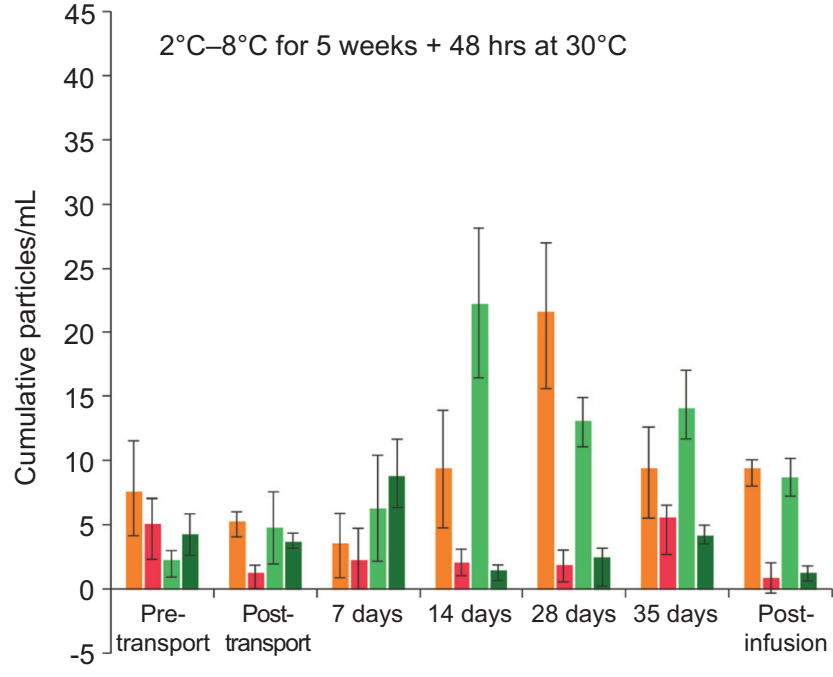

ABP 980 low dose

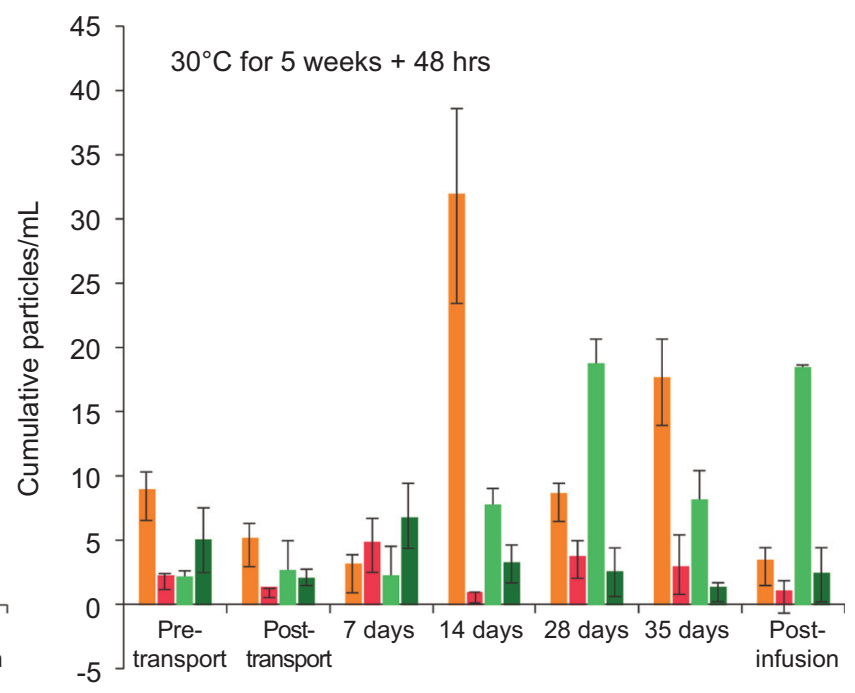

Trastuzumab low dose $\square$ Trastuzumab high dose

*Assessed by light obscuration by HIAC subvisible particle counting; data are a mean of triplicate assays $( \pm$ SD).

HIAC: high accuracy; SD: standard deviation. 


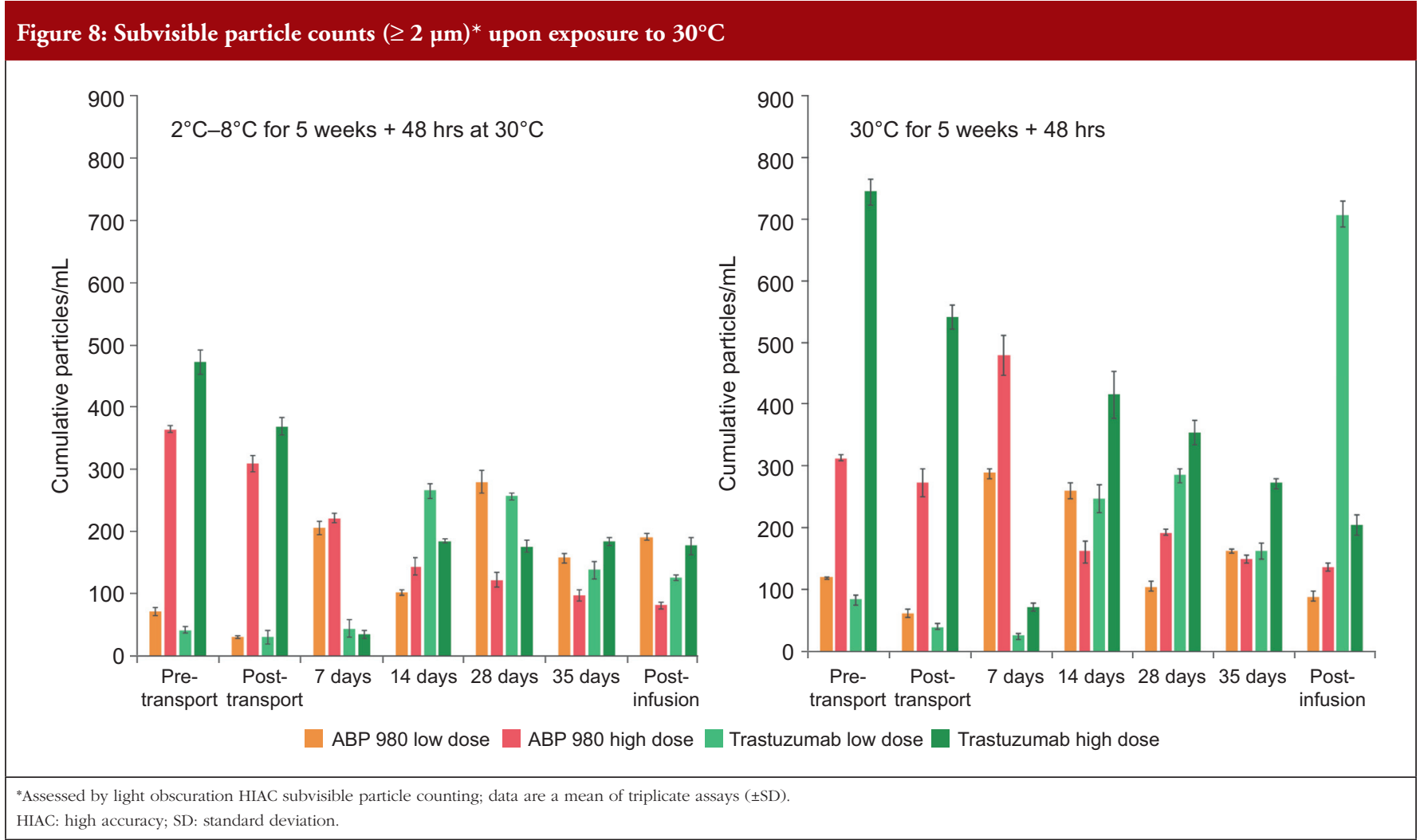

980, and that this may be of use when evaluating the impact of deviations in product handling [16].

Other studies have reported identical profiles for the extended stability of other monoclonal antibody biosimilars versus their reference products, e.g. infliximab and rituximab [17-19]. Another trastuzumab biosimilar has also shown extended stability after 1 month refrigerated storage followed by 24 hours at room temperature [20], and when stored in the dark at $4^{\circ} \mathrm{C}$ for 90 days [21]. In the latter study, while storage at $22^{\circ} \mathrm{C}$ for 28 days revealed slightly altered tertiary structures and signs of hydrolysis, as assessed by UV spectrometry and chromatography, there were no obvious signs of aggregate formation, as evaluated by turbidimetry [21]. However, the study reported here was the only study published to date to assess the impact of extended storage on biological activity and to compare the extended stability of the biosimilar directly to that of the reference product. In addition, this study evaluated the impact of mechanical stress on in-use stability, which more closely simulates real-world conditions. Reference trastuzumab IV solution has been found to remain physically and structurally stable at $2^{\circ} \mathrm{C}-8^{\circ} \mathrm{C}$ for 28 days [22] and up to 6 months [23]. A more recent study has indicated stability for 7 days when stored at $2^{\circ} \mathrm{C}$ to $8^{\circ} \mathrm{C}$, followed by an additional 24 hours at $30^{\circ} \mathrm{C}$ [24]. Although we did not use spectroscopy techniques to evaluate the impact of extended storage on tertiary structure, the combination of chromatography and biological assay techniques selected for this study provide a reliable assessment of higher order structure integrity. In addition, a previous publication reported that the higher order structures of ABP 980 and reference trastuzumab were highly similar [8]. Overall, our results compare favourably with previously published stability studies and provide additional insight by comparing the in-use extended stability of ABP 980 directly with that of reference trastuzumab.

Our findings support advance preparation of ABP 980 infusion bags at dosages of $0.3 \mathrm{mg} / \mathrm{mL}-3.8 \mathrm{mg} / \mathrm{mL}$ in saline solution, and storage for 35 days at $2^{\circ} \mathrm{C}-8^{\circ} \mathrm{C}$. These conditions have potential benefits for healthcare systems. For example, extended storage of ABP 980 infusion bags at $2^{\circ} \mathrm{C}-8^{\circ} \mathrm{C}$ could reduce workload for both pharmacies and nurses, provide dose-banding flexibility, reduce drug wastage; and improve patient management. In addition, the ability to transport and store ABP 980 to satellite clinics or pharmacies might allow patients to be treated closer to home.

One limitation of our study is that sterility was not evaluated. However, the high and low dose dilutions were prepared under aseptic conditions, and no bacterial or fungal contamination had been reported in a similar study of the trastuzumab biosimilar CT-P6 [21].

After our study had commenced, guidance from the UK National Health Service Pharmaceutical Quality Assurance Committee regarding how the stability of biopharmaceuticals might be derived and assessed, recommended a minimum of three replicates at each timepoint [25]. The lack of duplicates in some parts of our study and the lack of statistical comparison versus reference product is therefore a limitation of the study. However, we tested both ABP 980 and reference trastuzumab at two different concentrations and at two different temperatures, which provides a robust overall assessment of the stability profile and comparison between ABP 980 and reference 
trastuzumab. While $\mathrm{pH}$ was only measured at one timepoint, significant changes in $\mathrm{pH}$ would likely cause instability of the products that would have been detected in other tests. The fact that both products showed very similar behaviours in all the tests performed is reassuring.

\section{Conclusion}

Using a wide range of stability-indicating assays, this study has demonstrated the extended in-use stability of ABP 980. There was no meaningful impact on product quality of ABP 980 and reference trastuzumab under simulated real-life transportation and extended storage conditions at $2^{\circ} \mathrm{C}-8^{\circ} \mathrm{C}$ and $30^{\circ} \mathrm{C}$. These data also provide a comprehensive overview of the extended stability and activity of the trastuzumab biosimilar ABP 980 after dilution in IV bags. Provided that sterile conditions and appropriate quality controls are followed, the extended stability of ABP 980 at $2^{\circ} \mathrm{C}-8^{\circ} \mathrm{C}$ could improve cost-efficiency by enabling increased storage flexibility, including advance batch preparation, dose-banding (low- and high-dose preparations), reduced drug wastage, and workload optimization.

\section{For patients}

Once drug infusions are prepared, the way that they are stored and transported might affect whether they work as well as they should. It is important that, after storage and transportation, the drug being given is of the same quality and that the amount of drug remains stable. This paper has tested how the storage and transportation of two drug infusions made up of low and high doses of KANJINTI ${ }^{\mathrm{TM}}$ and Herceptin (essentially the same drug, called trastuzumab), affects their quality and stability. This study found that the quality and stability of both drugs was the same after mimicking transport in a truck, and after storage in a fridge or at room temperature. These findings mean that once these drug infusions are prepared at the specialist hospital pharmacy, they can be shipped out to local clinics where they can be given to you, saving you having to travel to a specialist hospital. It also helps saving time and money, as drug infusions could be prepared in advance and kept in storage in a refrigerator for a period of time.

\section{Acknowledgements}

Medical writing support (funded by Amgen Europe $\mathrm{GmbH}$, Rotkreuz, Switzerland) was provided by Sandra Cuscó, PhD, and Carolyn Bowler, PhD (Bioscript Medical Ltd, Macclesfield, UK).

We would also like to thank Linda Lai (Amgen, Thousand Oaks, CA, USA) for providing guidance and direction for the study.

\section{Funding sources}

This study was funded by Amgen Inc.

Competing interests: All authors are employees of Amgen and hold Amgen stock.

Provenance and peer review: Not commissioned; externally peer reviewed.

\author{
Authors \\ Shon Crampton ${ }^{1}$, BA \\ Alla Polozova ${ }^{1}, \mathrm{PhD}$
}

Darin Asbury ${ }^{2}$, BS

Alexis Lueras², BS

Paul Breslin ${ }^{1}$, BS

Jane Hippenmeyer ${ }^{3}$, PharmD

Jennifer Litowski ${ }^{1}, \mathrm{PhD}$

Monica Goss ${ }^{2}$, PhD

${ }^{1}$ Amgen Inc, 360 Binney Street, Cambridge, MA 02142, USA

${ }^{2}$ Amgen Inc, 1 Amgen Center Drive, Thousand Oaks, CA 91320, USA

${ }^{3}$ Amgen (Europe) GmbH, 22 Suurstoffi, CH-6343 Rotkreuz, Switzerland

\section{References}

1. U.S. Food and Drug Administration. Trastuzumab (Herceptin $\left.{ }^{\circledR}\right)$ : full prescribing information 1998 [homepage on the Internet]. [cited 2020 Jan 23]. Available from: https://www.accessdata.fda.gov/drugsatfda_docs/label/2010/ 103792s5250lbl pdf [Accessed 24th September 2019].

2. European Medicines Agency. Trastuzumab (Herceptin ${ }^{\circledR}$ ): EPAR summary for the public 2011 [homepage on the Internet]. [cited 2020 Jan 23]. Available from: https://www.ema.europa.eu/en/medicines/human/EPAR/herceptin [Accessed 24th September 2019].

3. Hudis CA. Trastuzumab--mechanism of action and use in clinical practice. N Engl J Med. 2007;357(1):39-51.

4. Barbier L, Declerck P, Simoens S, Neven P, Vulto AG, Huys I. The arrival of biosimilar monoclonal antibodies in oncology: clinical studies for trastuzumab biosimilars. Br J Cancer. 2019;121(3):199-210.

5. Markus R, Liu J, Ramchandani M, Landa D, Born T, Kaur P. Developing the totality of evidence for biosimilars: regulatory considerations and building confidence for the healthcare community. BioDrugs. 2017;31(3):175-87.

6. U.S. Food and Drug Administration. ABP 980 (trastuzumab biosimilar, KANJINTI $^{\mathrm{TM}}$ ): full prescribing information. 2019 [homepage on the Internet]. [cited 2020 Jan 23]. Available from: https://www.accessdata.fda.gov/drugsatfda_ docs/label/2019/761073s000lbl.pdf [Accessed 24th September 2019].

7. European Medicines Agency. Summary of opinion (initial authorisation): Kanjinti (trastuzumab). 2018 [homepage on the Internet]. [cited 2020 Jan 23]. Available from: https://www.ema.europa.eu/en/documents/smop-initial/ chmp-summary-positive-opinion-kanjinti_en.pdf [Accessed 24th September 2019].

8. Hutterer KM, Polozova A, Kuhns S, McBride HJ, Cao X, Liu J. Assessing analytical and functional similarity of proposed Amgen biosimilar ABP 980 to trastuzumab. BioDrugs. 2019;33(3):321-33.

9. Hanes V, Chow V, Zhang N, Markus R. A randomized, single-blind, singledose study evaluating the pharmacokinetic equivalence of proposed biosimilar ABP 980 and trastuzumab in healthy male subjects. Cancer Chemother Pharmacol. 2017;79(5):881-8.

10. European Medicines Agency. Herceptin: summary of product characteristics. 2019 [homepage on the Internet]. cited [2020 Jan 23]. Available from: https:// www.ema.europa.eu/en/documents/product-information/herceptin-eparproduct-information_en.pdf [Accessed 2nd April 2020].

11. European Medicines Agency. Kanjinti: summary of product characteristics. 2019 [homepage on the Internet]. cited [2020 Jan 23]. Available from: https:// www.ema.europa.eu/en/documents/product-information/kanjinti-epar-product-information_en.pdf [Accessed 2nd April 2020].

12. von Minckwitz G, Colleoni M, Kolberg HC, Morales S, Santi P, Tomasevic Z, et al. Efficacy and safety of ABP 980 compared with reference trastuzumab in women with HER2-positive early breast cancer (LILAC study): a randomised, double-blind, phase 3 trial. Lancet Oncol. 2018;19(7):987-98.

13. Bardin C, Astier A, Vulto A, Sewell G, Vigneron J, Trittler R, et al. Guidelines 
for the practical stability studies of anticancer drugs: a European consensus conference. Ann Pharm Fr. 2011;69(4):221-31.

14. Harris RJ, Kabakoff B, Macchi FD, Shen FJ, Kwong M, Andya JD, et al. Identification of multiple sources of charge heterogeneity in a recombinant antibody. J Chromatogr B Biomed Sci Appl. 2001;752(2):233-45.

15. Wang W, Singh S, Zeng DL, King K, Nema S. Antibody structure, instability, and formulation. J Pharm Sci. 2007;96(1):1-26.

16. Torbay and South Devon NHS Foundation Trust. Review of Trastuzumab biosimilar ABP 980 IV bag extended use stability study. Reference TRPT031413. 2018.

17. Lamanna WC, Heller K, Schneider D, Guerrasio R, Hampl V, Fritsch C, et al. The in-use stability of the rituximab biosimilar Rixathon ${ }^{\circledast} /$ Riximyo $^{\varpi}$ upon preparation for intravenous infusion. J Oncol Pharm Pract. 2019;25(2):269-78.

18. Vieillard V, Astier A, Sauzay C, Paul M. One-month stability study of a biosimilar of infliximab (Remsima ${ }^{\circledR}$ ) after dilution and storage at $4{ }^{\circ} \mathrm{C}$ and $25^{\circ} \mathrm{C}$. Ann Pharm Fr. 2017 Jan;75(1):17-29. doi:10.1016/j.pharma.2016.08.002.

19. Vieillard V, Paul M, Ibrahim T, Astier A. Extended stability of the rituximab biosimilar CT-P10 in its opened vials and after dilution and storage in polyolefin bags. Ann Pharm Fr. 2017;75(6):420-35.

20. Kim SJ, Lee JW, Kang HY, Kim SY, Shin YK, K WK, et al. In-use physicochemical and biological stability of the trastuzumab biosimilar CT-P6 upon preparation for intravenous infusion. BioDrugs. 2018;32(6):619-25.

21. Vieillard V, Astier A, Paul M. Extended stability of a biosimilar of trastuzumab (CT-P6) after reconstitution in vials, dilution in polyolefin bags and storage at various temperatures. Generics and Biosimilars Initiative Journal (GaBI Journal). 2018;7(3):101-10. doi:10.5639/gabij.2018.0703.022

22. Pabari RM, Ryan B, Ahmad W, Ramtoola Z. Physical and structural stability of the monoclonal antibody, trastuzumab $\left(\right.$ Herceptin $\left.^{\circledast}\right)$, intravenous solutions. Curr Pharm Biotechnol. 2013;14(2):220-5.

23. Paul M, Vieillard V, Da Silva Lemos R, Escalup L, Astier A. Long-term physicochemical stability of diluted trastuzumab. Int J Pharm. 2013;448(1):101-4.

24. Nalenz H, Köpf E, Dietel E. Prolonged in-use stability of reconstituted Herceptin in commercial intravenous bags. Int J Pharm Compd. 2018;22(5):417-23.

25. NHS Pharmaceutical Quality Assurance Committee. A standard protocol for deriving and assessment of stability, Part 2: aseptic preparations (biopharmaceuticals). 2017 [homepage on the Internet]. [cited 2020 Jan 23]. Available from: https://www.sps.nhs.uk/articles/standard-protocol-for-deriving-and-assessment-of-stability-part-2-aseptic-preparations-biopharmaceuticals-edition-2-2015yellow-cover/ [Accessed 24th September 2019].

DOI: $10.5639 /$ gabij.2020.0901.002

Copyright @ 2020 Pro Pharma Communications International 